\title{
Prevalence study of Legionella spp. contamination in ferries and cruise ships
}

\author{
Antonio Azara, Andrea Piana*, Giovanni Sotgiu, Marco Dettori, \\ Maria Grazia Deriu, Maria Dolores Masia, Bianca Maria Are and \\ Elena Muresu
}

Address: Hygiene and Preventive Medicine Institute, University of Sassari, Sassari, Italy

Email: Antonio Azara - azara@uniss.it; Andrea Piana* - piana@uniss.it; Giovanni Sotgiu - gsotgiu@uniss.it; Marco Dettori - igiene@uniss.it; Maria Grazia Deriu - igiene@uniss.it; Maria Dolores Masia - mdmasia@uniss.it; Bianca Maria Are - arebm@uniss.it;

Elena Muresu - muresu@uniss.it

* Corresponding author

Published: 18 April 2006

BMC Public Health2006, 6:100 doi:10.1 I86/147/-2458-6-100

This article is available from: http://www.biomedcentral.com/I47I-2458/6/100

(c) 2006Azara et al; licensee BioMed Central Ltd.

This is an Open Access article distributed under the terms of the Creative Commons Attribution License (http://creativecommons.org/licenses/by/2.0), which permits unrestricted use, distribution, and reproduction in any medium, provided the original work is properly cited.

\begin{abstract}
Background: In the last years, international traffic volume has significantly increased, raising the risk for acquisition of infectious diseases. Among travel-associated infections, increased incidence of legionellosis has been reported among travellers.

Aim of our study was: to describe the frequency and severity of Legionella spp. contamination in ferries and cruise ships; to compare the levels of contamination with those indicated by the Italian ministerial guidelines for control and prevention of legionellosis, in order to assess health risks and to adopt control measures.
\end{abstract}

Method: A prevalence study was carried out on 9 ships docked at the seaports of northern Sardinia in 2004. Water samples were collected from critical sites: passenger cabins, crew cabins, kitchens, coffee bars, rooms of the central air conditioning system. It was performed a qualitative and quantitative identification of Legionella spp. and a chemical, physical and bacteriological analysis of water samples.

Results: Forty-two percent (38/90) water samples were contaminated by Legionella spp.. Positive samples were mainly drawn from showers (24/44), washbasins (10/22). L. pneumophila was isolated in $42 / 44$ samples (95.5\%), followed by L. micdadei (4.5\%).

Strains were identified as $L$. pneumophila serogroup 6 (45.2\%; 19 samples), $2-14$ (42.9\%), 5 (7.I\%) and 3 (4.8\%). Legionella spp. load was high; $77.8 \%$ of the water samples contained $>10^{4} \mathrm{CFU} / \mathrm{L}$.

Low residual free chlorine concentration $(0-0,2 \mathrm{mg} / \mathrm{L})$ was associated to a contamination of the $50 \%$ of the water samples.

Conclusion: Legionella is an ubiquitous bacterium that could create problems for public health.

We identified Legionella spp. in 6/7 ferries. Microbial load was predominantly high (>104 CFU/L or ranging from $10^{3}$ to $10^{4} \mathrm{CFU} /$ $\mathrm{L})$. It is matter of concern when passengers are subjects at risk because of Legionella spp. is an opportunist that can survive in freshwater systems; high bacterial load might be an important variable related to disease's occurrence.

High level of contamination required disinfecting measures, but does not lead to a definitive solution to the problem. Therefore, it is important to identify a person responsible for health safety in order to control the risk from exposure and to apply preventive measures, according to European and Italian guidelines. 


\section{Background}

Tourism has played an important role in economic growth in Developed and Developing Countries.

According to the data of the body representing the private sector in all parts of the travel and tourism industry worldwide, i.e. the World Travel and Tourism Council, travel and tourism industry contribute $10.9 \%$ of gross international product $[1,2]$.

Tourism has contributed significantly towards the Italian economic development; the impact on economy is estimated at 350 billions euros in the next ten years [2].

However, an increased risk for acquisition of diseases, such as those related to infection, is inevitably associated with the international traffic volume, as well as with the modern high-speed transport (high disease burden in developing countries).

Among travel-associated infections, increased incidence of legionellosis, infection caused by the bacterium Legionella spp., has been reported among travellers; at least 48 species of Legionella have been identified, with 18 of these species linked to human diseases [3]. L pneumophila is the most frequent cause of human legionellosis.

Legionellosis refers to 2 distinct clinical syndromes, namely, Legionnaires disease, which most often presents as severe pneumonia accompanied by multisystemic disease, and Pontiac fever, which is an acute, febrile, self-limited, viral-like illness [4].

Legionella are gram-negative, rod-shaped bacteria that are ubiquitous in freshwater environments. Transmission occurs through aerosolization or aspiration of contaminated water [5]. Infection depends on the water contamination level by bacteria, host factors (advanced age, tobacco smoke, chronic degenerative diseases, state of immunodeficiency), and the virulence of the particular strain of Legionella (enhanced by protozoa- or amoeba-bacterium relationship).

Most cases of Legionellosis are sporadic but outbreaks can occur due to contamination of hot and cold water systems, evaporative condensers, spa pools/natural pools/ thermal springs, respiratory therapy equipment. Biofilm formation can provide a means for survival and dissemination of Legionella bacterium [6,7].

Cases might be linked to nosocomial-lethality rate: $30-$ $50 \%$ - or travel-associated infection (tourist accommodation, vessel, etc.).
Owing to the possibility of environmental exposure to the organism, legionellosis is a public health problem, investigated by numerous health organizations, such as the World Health Organization (WHO), European Working Group for Legionella Infections (E.W.G.L.I) [8], Italian Istituto Superiore di Sanità.

On this basis, to assess the impact of Legionella spp. contamination in vessels, Hygiene and Preventive Medicine Institute of the University of Sassari, Italy, involved in the surveillance of nosocomial legionellosis in the last years, together with Maritime Health Office of Porto Torres, Italy, undertook an epidemiological investigation of ferries and cruise ships.

It addressed two aims: - to describe the frequency and severity of Legionella spp. contamination; - to compare the levels of contamination with those indicated by the Italian ministerial guidelines for control and prevention of legionellosis, in order to assess health risks and to adopt control measures.

\section{Methods}

The survey was carried out on 9 ships docked at the seaports of northern Sardinia in 2004; 7 ferries belonged to two Italian shipping companies while 2 cruise ships belonged one to an Italian shipping company and another come from Bahamas. Epidemiological investigation was divided into three distinct types of activity:

- selection of suspected contaminated areas and their critical sites; particularly, five different areas were identified: cabin where people sleep, cabin where crew sleep, kitchen, coffee bar, room of the central air conditioning system. Water samples were collected from showers, washbasins, kitchen sinks, evaporative condensers of air conditioning systems.

- water sampling: two samples were collected from every sampling site in a single time-point (total amount = 90; ten samples were collected from every ship, five for qualitative and five for quantitative identification of Legionella spp). The first water sample was collected for qualitative evaluation, without flaming and immediately after the tap was switched on; the second sample was collected for quantitative analysis, after the water ran for at least 5-10 minutes, being more representative of the water flowing in the system.

- qualitative and quantitative analysis of Legionella spp, according to methods described in the guidelines for prevention and control legionellosis [9-11]; furthermore, determination of water quality was carried out in order to enumerate total and fecal coliforms, fecal streptococci, sulphate-reducing clostridi. Total microbial counts were evalu- 


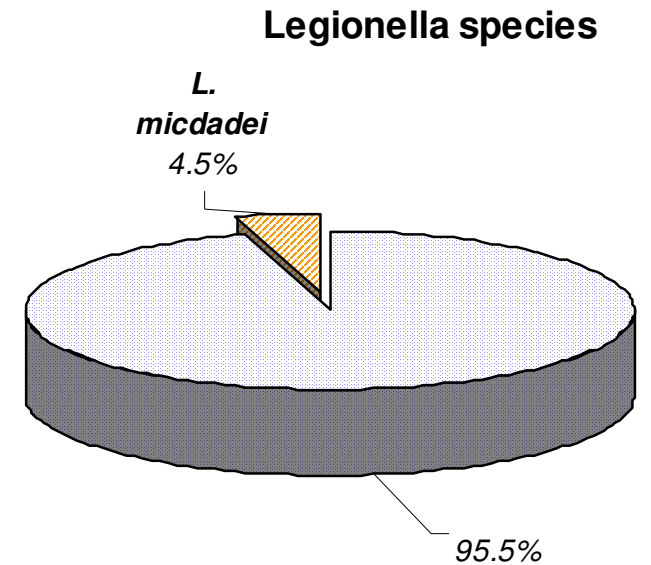

\section{Legionella species}

\author{
L. pneumophila
}

\section{L. pneumophila serogroups}

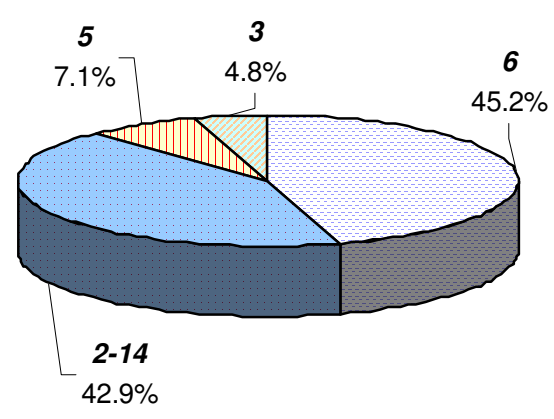

\section{Figure I}

Legionella identification: species and serogroups.

ated at $22^{\circ} \mathrm{C}$ and $37^{\circ} \mathrm{C}$. Water temperature and residual free and totalchlorine were determined at the time of sample collection.

Briefly, one litre water samples were collected in sterile containers containing $0.01 \%$ sodium thiosulphate to neutralise any chlorine; they were kept at ambient temperature and protected from direct light. Water was processed on the day of collection and sample concentration was conducted using $0.45 \mu \mathrm{m}$ cellulose membrane filters.

After concentration, the membranes were aseptically removed and placed into sterile screw-capped containers with $10 \mathrm{ml}$ sterile distilled water. The material of the filter membrane was vortex-mixed (3 times for $30 \mathrm{sec}$ ).

Then, a $0.1 \mathrm{ml}$ of each sample was inoculated onto two GVPC-selective agar, a medium containing cycloheximide, glycine, polymyxin $\mathrm{B}$ and vancomycin.

The remaining $9.9 \mathrm{ml}$ was centrifuged at 3,000 $\mathrm{R} / \mathrm{min}$ for 20 minutes; all the supernatant was removed but $1 \mathrm{ml}$; then, the sediment was resuspended and incubated at $50^{\circ} \mathrm{C}$ in a water bath for $30 \mathrm{~min}$; afterwards, $0.1 \mathrm{ml}$ was spread on duplicate plates of GVPC agar. These plates, laid into candle jars, were incubated at $36-37^{\circ} \mathrm{C}$ in a humidified atmosphere with $<5 \% \mathrm{CO} 2$.

Plates were evaluated for 10 days before reporting them negative.
Gram stain was performed in case of suspected colonies; weakly staining, gram-negative bacilli were observable. Suspected colonies with a mottled surface or an iridescent and faceted cut glass appearance, were counted from each sampling. All colonies from plates with $\leq 10$ and 10-20 random colonies were subcultured on buffered charcoal yeast extract (BCYE) agar (with cysteine), charcoal yeast extract agar (CYE Agar Base - Oxoid), blood-agar and McConkey agar plates.

These plates were incubated at $37^{\circ} \mathrm{C}$ in a humidified environment for $\geq 2$ days. Only colonies grown on BCYE were subsequently identified by two agglutination tests (i.e., Legionella Latex Test, Oxoid and Legionella Immune Sera "Seiken", Denka Seiken Co. LTD). The first test allows a separate identification of L. pneumophila serogroup 1 and serogroups 2-14 and detection of seven Legionella species (Legionella spp. group), which have been implicated in human disease: L. longbeachae 1 and 2, L. bozemanii 1 and 2, L. dumoffii, L. gormanii, L. jordanis, L. micdadei, L. anisa. The second test identifies Legionella pneumophila serogroup 1, 2, 3, 4, 5, 6 and L. bozemanii, L. dumoffii, L. gormanii, L. micdadei.

\section{Results}

An elevated number of samples was collected from areas and critical sites at risk (cabin where people sleep; cabin where crew sleep; showers, washbasins, kitchen sinks), considering the modes of transmission of Legionella infection. 


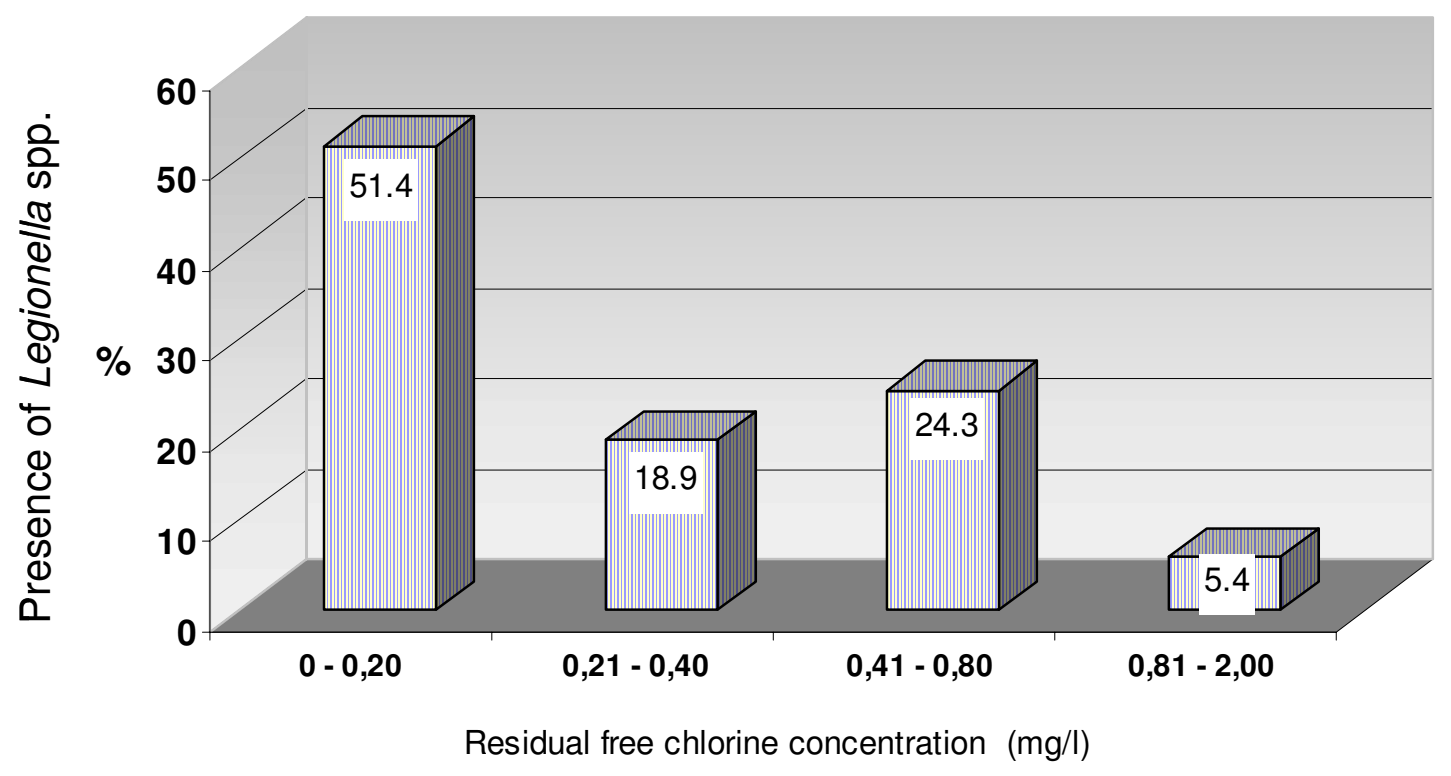

Figure 2

Relation between residual free chlorine concentration and presence of Legionella spp. in water samples.

A total of $34(37.8 \%)$ samples of 90 were collected from cabins where people sleep, 32 (35.6\%) from cabins where crew sleep, $16(17.8 \%)$ from kitchens, $6(6.7 \%)$ from coffee bars and $2(2.2 \%)$ from air conditioning system rooms (table 1); a total of $44(48.8 \%)$ samples of 90 were drawn from showers, 22 (24.5\%) from washbasins, 22 (24.5\%) from kitchen sinks and 2 (2.2\%) from evaporative condensers of air conditioning systems (table 1).

Legionella spp. was identified in all but one ferries (66\% of the total ships), while cruiser ships were not contaminated. An average of four samples (range, $0-10$ ) was positive per ship.

A total of $38(42.2 \%)$ water samples of 90 were contaminated by Legionella spp. (table 1): 50\% (17/34) collected from cabins where people sleep, 53.1\% (17/32) from cabins where crew sleep, $12.5 \%$ (2/16) from kitchens, 33.3\% $(2 / 6)$ from coffee bars; it was not identified in water samples collected in the air conditioning system rooms.

Positive samples were drawn from showers (24/44; $54.5 \%)$, mainly those located in cabins where crew sleep, from washbasins $(10 / 22 ; 45.5 \%)$, mainly those located in cabins where people sleep (60\%), from kitchen sinks (4/ $22 ; 18.2 \%)$, mainly those located in coffee bars (33.3\%).
L. pneumophila was isolated in $42 / 44$ samples $(95.5 \%)$, followed by L. micdadei (4.5\%). (figure 1)

Strains were identified as $L$. pneumophila serogroup 6 (45.2\%; 19 samples), $2-14$ (42.9\%), 5 (7.1\%) and 3 $(4.8 \%)$. (figure 1$)$.

Legionella spp. load was high: $22.2 \%$ contained $1 \times 10^{3}-$ $1 \times 10^{4}$ Legionella per litre, while $50 \% 1 \times 10^{4}-1 \times 10^{5}$, $22.2 \% 1 \times 10^{5}-1 \times 10^{6}, 5.6 \% 1 \times 10^{5}-1 \times 10^{6}$. Then, $27.8 \%$ contained $>100,000$ Legionella per litre which is judged the critical level for environmental decontamination in absence of Legionnaires' disease, according to Italian guidelines.

Detection of microbial indicators of faecal contamination and total microbial counts at $22^{\circ} \mathrm{C}$ and $37^{\circ} \mathrm{C}$ were performed (25); bacterial load wasvariable ranging from 0 to $1,000 \mathrm{CFU} / \mathrm{ml}$ and from 0 to $784 \mathrm{CFU} / \mathrm{ml}$ at $37^{\circ} \mathrm{C}$ and $22^{\circ} \mathrm{C}$, respectively, independently of Legionella spp. growth; it was demonstrated no link between microbial count and the presence of Legionella spp. in water samples. In only one sample microbial counts were 230 and 768 $\mathrm{CFU} / 100 \mathrm{ml}$ at $37^{\circ} \mathrm{C}$ and $22^{\circ} \mathrm{C}$, respectively, in wich total and fecal coliforms were isolated (30 and $8 \mathrm{CFU} / 100 \mathrm{ml}$, respectively) but not Legionella spp.. 
We examined the relation between residual free chlorine and Legionella spp.: 0-0.2 mg/L residual free chlorine concentration was associated to a contamination of the $50 \%$ of the water samples, $0.81-2 \mathrm{mg} / \mathrm{L}$ to $5.4 \%$; Legionella spp. did not significantly decrease in association to a residual free chlorine concentration of $0.21-0.80 \mathrm{mg} / \mathrm{L}$ (figure 2).

Water temperature of Legionella spp. positive samples ranged from $20^{\circ} \mathrm{C}$ to $40^{\circ} \mathrm{C}\left(50 \%\right.$ ranging from $20^{\circ} \mathrm{C}$ to $30^{\circ} \mathrm{C}$ and $50 \%$ ranging from $31^{\circ} \mathrm{C}$ to $40^{\circ} \mathrm{C}$ ); Legionella spp. was not identified in water samples whose temperature ranged from $41^{\circ} \mathrm{C}$ to $60^{\circ} \mathrm{C}$.

Of the 90 water samples, six (6.6\%), collected in a single cruise-ship, had temperature ranging from 42.4 to $56.6^{\circ} \mathrm{C}$. Negative cultures of these water samples might be due to their residual free and total chlorine, ranging from 1.80 to 1.95 and from 1.90 to $>2$, respectively.

\section{Discussion}

Legionella is an ubiquitous bacterium that could create problems for public health; most cases of Legionnaire's disease are sporadic but nosocomial or community outbreaks can occur, such as those related to tourist accommodations [12-15].

We conducted a prevalence study in order to evaluate the presence of Legionella spp. in passenger vessels, i.e. ferries and cruise ships, because of the increased navigation traffic and poor national and international medical reference.

We analysed 2 cruise ships and 7 ferries; Legionella spp. was identified in 6/7 ferries. Microbial load was predominantly high (> $10^{4} \mathrm{CFU} / \mathrm{L}$ or ranging from $10^{3}$ to $10^{4} \mathrm{CFU} /$ L).

However, we did not identify Legionella pneumophila serogroup 1, which is responsible for more than $90 \%$ of clinical cases.

This finding might be related to differences in environmental prevalence among Legionella pneumophila serogroup 1 and non-pneumophila species. Several reports, evidenced that the high frequency of Legionella pneumophila serogroup 1 isolation from clinical samples is not strictly linked to environmental predominance but might be due to higher infectivity or more efficient intracellular growth. The low incidence of non-pneumophila species among clinical isolates associated to their high environmental frequency implies that these species are less virulent and pathogenic than Legionella pneumophila serogroup 1 [16].

It is matter of concern when passengers are subjects at risk (smokers, older people, immunocompromised individu- als, etc.); Legionella spp., in fact, is an opportunist par excellence, that can survive in freshwater systems; high bacterial load might be an important variable related to disease's occurrence in association to long-term exposure.

Although cruise ships were Legionella spp.-free, ferries to Sardinia are frequently used for cruising during all seasons but summer.

Therefore, it is important to analyse the risk of acquiring infection with regard to water supplies and hosts in order to provide preventive interventions.

According to recent Italian guidelines targeted to administrators of hotels and thermal baths, contamination level is high in $77.8 \%$ of our samples, requiring disinfecting measures and later evaluation, regardless of disease's occurrence; the remaining samples $(22.2 \%)$ have to be surveyed, requiring decontamination measures if one or more cases of legionellosis are identified [10].

Prophylactic measures, as stated by EWGLI, imply that all water services should be routinely checked for temperature, water demand and inspected for cleanliness and use [8].

Principal items include the reduction of the possibility of using contaminated water by disinfecting (chemical disinfection), filtering and suitably storing the water; keeping cold water cold and hot water hot; avoiding the dead ends in pipes; properly cleaning and disinfecting spas; periodically cleaning or replacing the devices that might promote dissemination of Legionella.

\section{Conclusion}

The absence of a correct prevention of Legionella infections onboard ship might cause a lot of medical - sanitary, legal and economic problems (deaths, negative impact on tourism, possible removal of the ship from the service and suspension of activity of its crew for many days, etc.) $[8,13,17]$.

Furthermore, environmental decontamination is useful as punctual action but does not lead to a definitive solution to the problem.

Therefore, it is important to identify a person responsible for supervision and health safety in order to prevent or to control the risk from exposure, according to EWGLI and Italian guidelines; the person has to conduct an assessment of the sites at risk in the water systems present in the premises and to implement precautions for controlling any identified risk from Legionella bacteria. He has to be competent to assess the risks of exposure to Legionella bacteria in the water systems present in the premises and 
the control measures (e.g. a microbiologist, environmental health officer or water engineer with is specific expertise).

This aspect might be fundamental in Sardinia, an island devoted to tourism, where prevention of infectious disease acquisition from environmental sources and healthcare have to be associated to elevated level of quality of dwelling places.

Shipping companies have a keen interest in effects of our epidemiological study, showing willingness to proceed with investigation targeted to Legionella bacterium and to verify the efficacy of decontamination performed after the survey.

\section{Abbreviations \\ CFU: colony forming unit}

WHO: World Health Organization

EWGLI: European Working Group for Legionella Infections

\section{Competing interests}

The author(s) declares that he has no competing interests.

\section{Authors' contributions}

All of the authors participated in planning and design of the study, and all read and approved the manuscript. MD and MGD participated to the waters analysis. AA, AP, GS, MDM, BMA and EM conceived the study, participated in its design and wrote the manuscript.

\section{note}

Table 1 - Distribution of Legionella spp. in ferries and cruise ships.

\section{Acknowledgements}

The authors would like to thank the public health medical doctors and technical staff of Maritime and Airline Health Office (Porto Torres, Sardinia, Italy) of Italian Ministry of Health.

\section{References}

I. Gianvenuti A: Verso uno sviluppo sostenibile: il turismo sostenibile, strumento di sviluppo economico e di protezione ambientale. [http://www.runiceurope.org/italian/indicesitol docs contr.html].

2. World Tourism Organization [http://www.world-tourism.org/]

3. Fields BS, Benson RF, Besser RE: Legionella and Legionnaires' disease: 25 years of investigation. Clin Microbiol Rev 2002, I5(3):506-526.

4. Breimen RF, Butler JC: Legionnaires' Disease: clinical, epidemiological, and public health perspectives. Seminar in Respiratory Infections 1998, I 3(2):84-89.

5. Woo AH, Goetz A, Yu VL: Transmission of Legionella by respiratory equipment and aerosol generating devices. Chest 1992, 102:1586-1590.

6. Mattana A, Biancu G, Alberti L, Accardo A, Delogu G, Fiori PL, Cappuccinelli $P$ : In vitro evaluation of the effectiveness of the mac- rolide rokitamycin and chlorpromazine against Acanthamoeba castellanii. Antimicrob Agents Chemother 2004, 48( I 2):4520-4527.

7. Patterson WJ, Hay J, Seal DV, McLuckie JC: Colonization of transplant unit water supplies with Legionella and protozoa: precautions required to reduce the risk of Legionellosis. J Hosp Infect 1997, 37:7-I7.

8. EWGLI: European guidelines for control and prevention of travel associated Legionnaires' disease. 2002 [http:// www.ewgli.org/guidelinedownload].

9. Gazzetta Ufficiale n. 103 del 5 maggio 2000: Linee guida per la prevenzione e il controllo della Legionellosi. [http://www.guri tel.it/free-sum/ARTI/2000/05/05/sommario.html].

10. Gazzetta Ufficiale n. 28 del 4 febbraio 2005: Linee guida recanti indicazioni sulla Legionellosi per i gestori di strutture turistico-recettive e termali. [http://www.guritel.it/free-sum/ARTl/ 2005/02/04/sommario.html].

II. Gazzetta Ufficiale n. 29 del 5 febbraio 2005: Linee guida recanti indicazioni ai laboratori con attività di diagnosi microbiologica e controllo ambientale della Legionellosi. [http:// www.guritel.it/free-sum/ARTI/2005/02/05/sommario.html].

12. Ricketts K, Joseph C, European Working Group for Legionella Infections: Travel Associated Legionnaires' disease in Europe: 2003. Euro Surveill 2004, 9(10):40-43.

13. Cayla JA, Maldonado R, Gonzales J, Pellicer T, Ferrer D, Pelaz C, Gracia J, Baladron B, Plasencia A, Legionellosis study group: A small outbreak of Legionnaire's disease in a cargo ship under repair. Eur Resp Jun 200I, I7(6): I322-1327.

14. Jernigan DB, Hofmann J, Cetron MS, Genese CC, Nuorti JP, Fields BS, Benson RF, Carter RJ, Edelstein PH, Guerrero IC, Paul SM, Lipman HB, Breiman R: Outbreak of Legionnaire's disease among cruise ship passengers exposed to a contaminated whirlpool spa. Lancet 1996, 347:494-499.

15. Regan CM, McCann B, Syed Q, Christie P, Joseph C, Colligan J, McGaffin A: Outbreak of Legionnaires' disease on a cruise ship: lessons for international surveillance and control. Liverpool Health Authority. Commun Dis Public Health 2003, 6(2): $152-156$

16. Doleans A, Aurell H, Reyrolle M, Lina G, Freney J, Vandenesch F, Etienne J, Jarraud S: Clinical and environmental distributions of Legionella strains in France are different. J Clin Microbiol 2004, 42(I):458-60.

17. World Health Organization: Sanitation on ships. Compendium of outbreaks of foodborne and waterborne disease and Legionnaires' diseases associated with ships (1970-2000). [http://www.who.int/entity/water sanitation health/hygiene/ships/ en/shipsancomp.pdf].

\section{Pre-publication history}

The pre-publication history for this paper can be accessed here:

http://www.biomedcentral.com/1471-2458/6/100/pre pub

Publish with BioMed Central and every scientist can read your work free of charge

"BioMed Central will be the most significant development for disseminating the results of biomedical research in our lifetime. "

Sir Paul Nurse, Cancer Research UK

Your research papers will be:

- available free of charge to the entire biomedical community

- peer reviewed and published immediately upon acceptance

- cited in PubMed and archived on PubMed Central

- yours - you keep the copyright

Submit your manuscript here:

http://www.biomedcentral.com/info/publishing_adv.asp
BiolMedcentral 